WHOI-89-52

\title{
A Pop-up Float Recovery System For Coastal Oceanographic Tripods
}

by

Christopher V.R. Dunn and Allan G. Gordon

Woods Hole Oceanographic Institution

Woods Hole, Massachusetts 02543

November 1989

\section{Technical Report}

Funding was provided by the Office of Naval Research under contract No. N00014-89-J-1058.

Reproduction in whole or in part is permitted for any purpose of the United States Government. This report should be cited as:

Woods Hole Oceanog. Inst. Tech. Rept., WHOI-89-52.

Approved for publication; distribution unlimited.

\section{Approved for Distribution:}

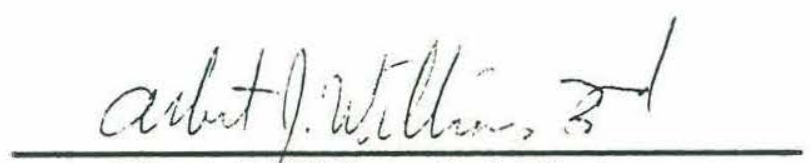

Albert J. Williams 3rd, Chairman

Department of Applied Ocean Physics and Engineering 


\section{Contents}

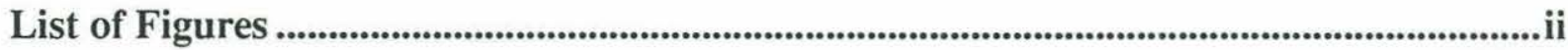

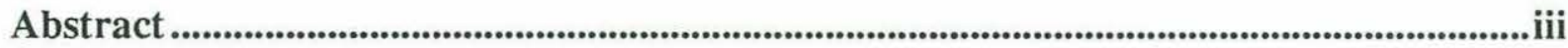

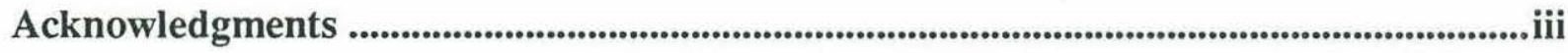

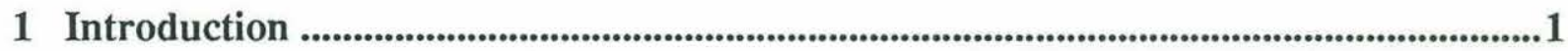

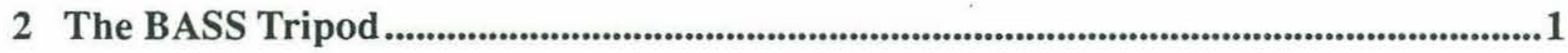

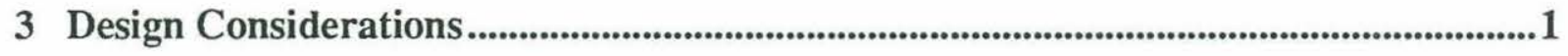

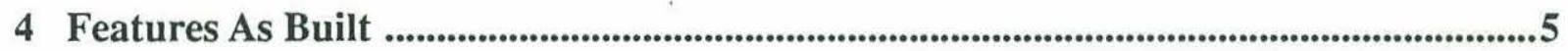

5 Field Experience

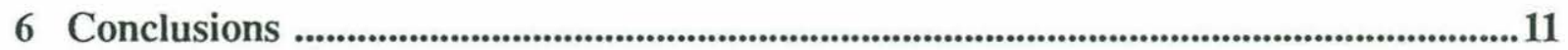

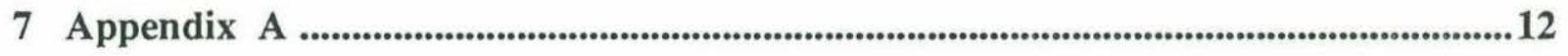

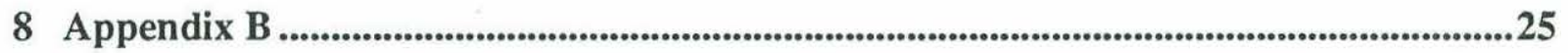




\section{List of Figures}

1 STRESS/SMILE Location . . . . . . . . . . . . . . . . 2

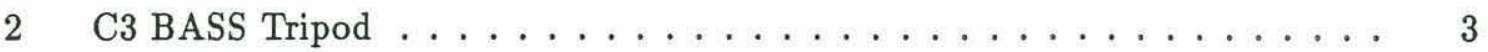

3 Completed Float Package ..................... 6

4 Drawing of Release Features . . . . . . . . . . . . . . 7

5 Illustration of Canister and Rope Packing Techniques . . . . . . . . . 9 


\begin{abstract}
The recovery package described here was used as the primary retrieval system to recover tripod instrument platforms from a depth of 90 meters. The device uses dual in-line burn wires, one of which is acoustically commanded from the surface ship. The other is set to release by back-up timer, ensuring recovery in the event of a poor acoustic command channel. The burn wire activates spring loaded cam latches which release the float package and pull a $\frac{1}{2}$ inch Dacron line to the surface. The float package is recovered and the line is used to winch the tripod to the surface for recovery by the ship's crane. Major benefits of the system are reliability, low cost, light weight, and use of many off-the-shelf components. The float package provides 50 pounds of buoyancy and is fabricated using commercial fish trawl net floats. The retrieval line container is separate from the float assembly, and is fabricated from plastic storage containers. The line is coiled and restricted to prevent unpackaging due to * waves or current action. The system described here is not appropriate in areas of high current or great depth due to drag and dead weight of the lift line.
\end{abstract}

\title{
Acknowledgments
}

The development of this pop-up float recovery system was made possible by the Office of Naval Research Grant Number N00014-89-J-1058. We acknowledge the encouragement and guidance of Albert J. Williams, 3rd and Yogesh C. Agrawal. We also would like to thank Ellyn T.Montgomery for her diver observations during dock site testing, and to Paul R. Boutin who arranged the remotely operated vehicle recovery of the single unsuccessful pop-up float retrieval. Special appreciation also is extended to Judith A. White for manuscript preparation and Betsy G. Pratt for art work. 


\section{Introduction}

The Sediment Transport Events on Shelves and Slopes (STRESS) experiment took place during the winter of 1988/1989 off the California coast north of San Francisco. The location is shown in Figure 1. An array of bottom tripods was deployed in approximately 90 meters of water in order to study the effects of winter storms on the transportation of sediment along the coast. The tripods carried instruments for measuring current, suspended sediment loads, and temperature structure. The tripods were deployed for a total of five months, but were recovered, serviced, and redeployed halfway through the experiment. This report describes a device used to recover the tripods from the ocean bottom during the STRESS experiment. The device is a command releasable float package which pulls a $1 / 2$ inch Dacron line to the sea surface. Once on the surface, the float package is recovered, and the line is used to winch the tripod to the surface where it is recovered using the ship's crane. The recovery device * functioned reliably, with a total of eight successes out of nine trials. A single tripod was recovered using a remotely operated vehicle (ROV) when the recovery line fouled on release and prevented the float package from reaching the surface.

\section{The BASS Tripod}

The tripods used in the STRESS experiment were originally designed for use in the deep ocean (Williams et al., 1987). A drawing of a tripod is shown in Figure 2. Typical deployment depths were on the order of 5000 meters, and locations were hundreds of miles from shore. In the deep ocean, a large base section from the tripod was dropped as an expendable anchor and the upper section only was recovered. In the remote locations there was no need to be concerned about the discarded anchor interfering with fishing or other bottom activities. The STRESS experimental site is located close to the California coast, and bases left on the bottom could present a hazard to fishing and navigation activities in that area. For this reason, we decided to modify the tripods so that they could be recovered with their anchor bases. During the Coastal Ocean Dynamics Experiment (CODE) in 1981 and 1982, smaller tripods had been deployed and successfully recovered using a commandable float and line release. This experience served as the basis for our design effort.

\section{Design Considerations}

Our experiences during CODE showed that we needed to develop a recovery device which featured a separate float and rope canister arrangement. In the coastal area, wave action causes the float package to oscillate while on the bottom. This action allows the rope canister to unpack and foul when it is sealed by the float package itself. To eliminate this possibility, we designed a rack for the float which incorporated the release mechanism, and a container for the lift line which is separate and nearly sealed to prevent unpacking as much as possible. 


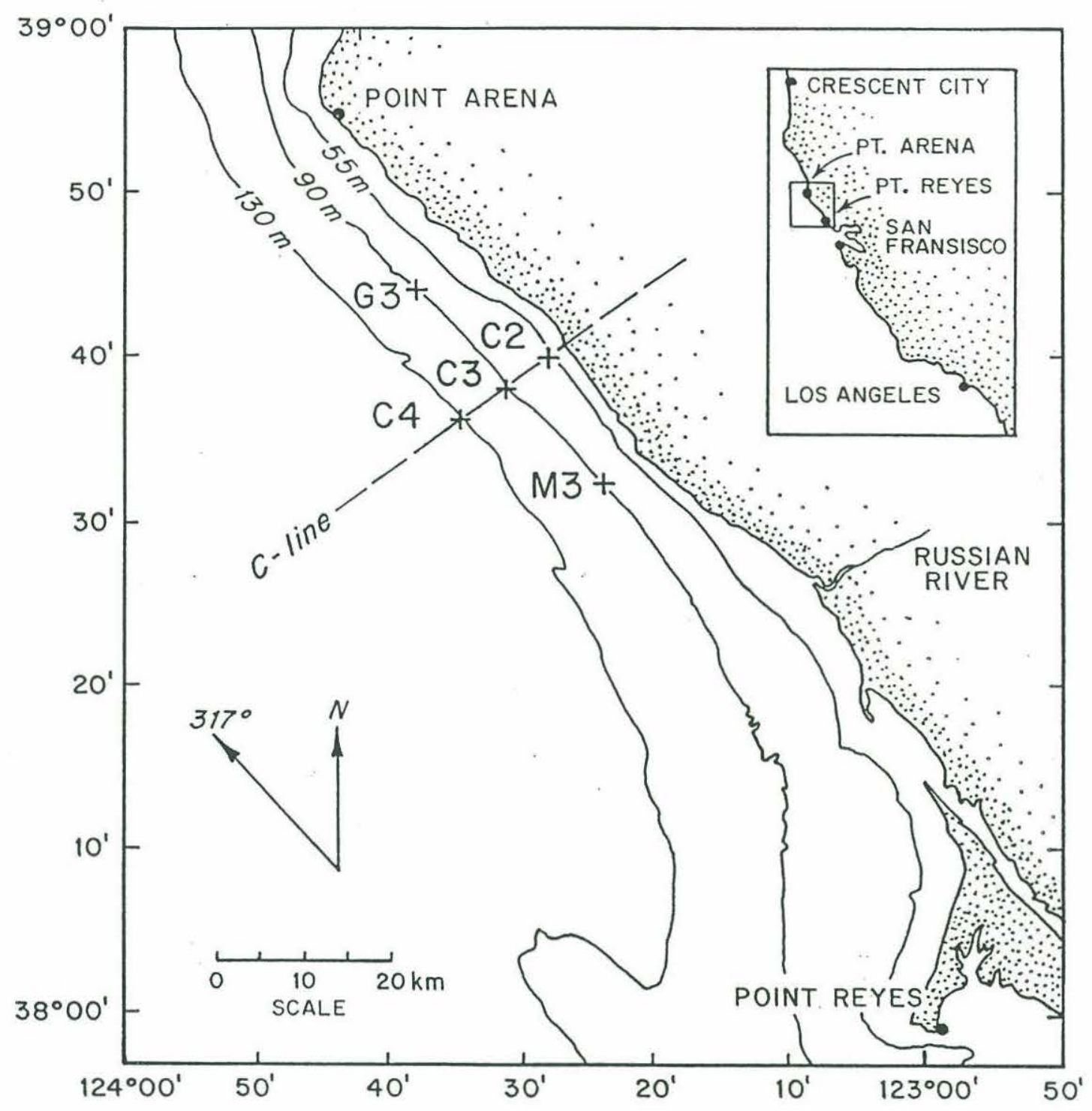

Figure 1: STRESS/SMILE Location 


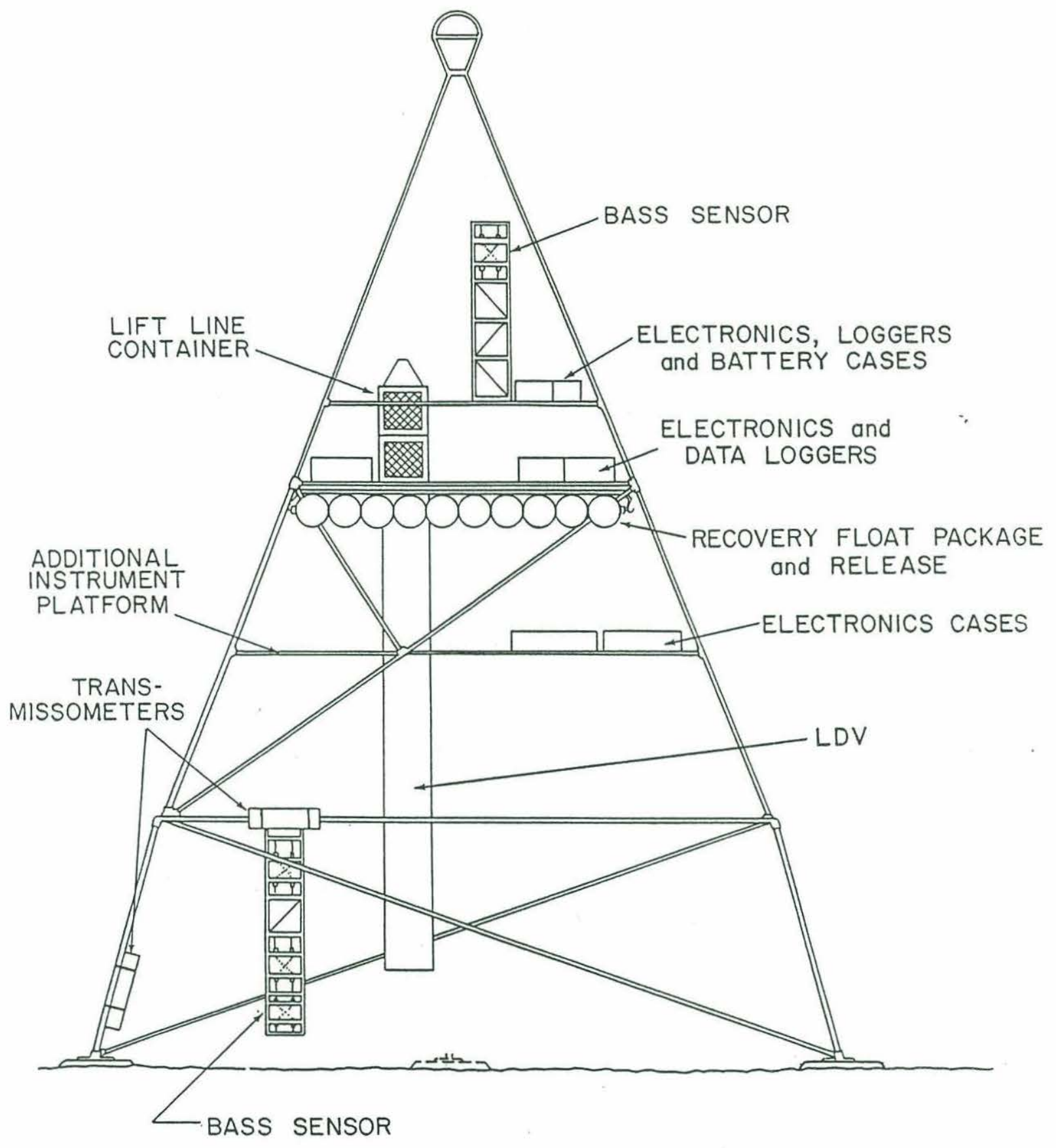

Figure 2: C3 BASS Tripod 
As a final measure, the lift line is secured to the tripod outside of the container using very low strength monofilament fish line to prevent any pumping of the contents by wave or current action.

It was also important to incorporate a true latch action into the design of the release. A true latch is a device which captures and contains a variable load without transmitting the load itself onto the member restraining the latch. This was accomplished in our design by carefully shaping the release cams so that loads from the float package were transferred to the cam axle, not the restraining cable.

Dual in line releases are considered to be a crucial element of any oceanographic release, allowing for successful operation in the event of a single release failure. Our design used electrically dissolved nichrome " burn" wires to provide the release capability. Two fully isolated wires are connected in series to the restraining member of the release so that they" can be "burned" individually by separate release units. The units are acoustically commanded from the surface ship, and can also be set to release on a back up timer to ensure release in the event of a poor acoustic command channel.

Another consideration in our design effort was to use low cost, lightweight, off the shelf components where possible. Flotation was provided by commercial mid-water fishing floats. These are available from a variety of commercial sources, are reasonably inexpensive, and provide adequate performance for the depths we were operating in. A single unit was pressure tested here at WHOI and found to have a collapse depth of approximately 1300 meters (1900 psi), well in excess of our 90 meter depth requirement. A total of ten seven inch diameter spherical floats were used to provide fifty pounds of positive buoyancy. The total cost for the floats was about $\$ 100$. This is considerably less than the cost of a glass sphere or syntactic foam float providing a similar amount of buoyancy.

The line canister was constructed from plastic milk crates lined with a heavy duty plastic mesh material. The mesh was intended to prevent the line from throwing a loop through the larger openings in the milk crates. The top of the canister was sealed with a lid consisting of a crate bottom and a large circular funnel. The funnel was inverted and had its opening enlarged to allow the line to pay out smoothly. The line itself was coiled evenly within the container in such a way to minimize the possibility of a loop catching in the funnel opening as the line payed out.

The use of plastic components meant that we were able to assemble the rope canisters using only hand tools and simple fabrication techniques. This design philosophy held true for the rest of the recovery system as well. The float package itself was assembled with aluminum tubing and stainless steel eyebolts. Three welds were required to complete the float package assembly. The float rack and latch were also constructed of aluminum and stainless components. The latch cam was the only part which required any type of complicated machining for assembly. The release springs and restraining cable were constructed with commercially available hardware. Zinc anodes were attached to the float rack for corrosion protection. 


\section{Features As Built}

The float package for the recovery system was fabricated with commercial midwater trawl floats. We selected the variety with a single hole through the center of the float, and captured ten of them on an aluminum pipe to form a package. The fishing floats were selected because they were inexpensive and readily available. In quantity, the floats can be purchased for about $\$ 10$ (1989) each. A drawing of the completed float package is shown in Figure 3.

Before assembling the float package, we performed a pressure test on a single float. The pressure test facility here at WHOI was used to compress a float until it imploded. The test proved that the float could withstand pressures equivalent to a collapse depth of approximately 1300 meters. Our requirement was to provide an operating depth of approximately 90 meters, which was well within the capabilities of the float selected. The test results indicated that we : would have a depth safety factor of about fifteen to one.

As a further test, the floats that were used in the field were subjected to slow leak tests. This was accomplished by storing the floats in the pressure test vessel for an extended time at approximately 65 PSI. The floats were weighed before and after the soaking to determine if any had gained weight due to seepage. None were discovered to have leaked, giving us confidence in our selection.

The float rack system was constructed from 6061 aluminum alloy. Channel section was used for the main structural component. Two V-notched stanchions were bolted to this backbone to provide location and support for the float package, which was secured by two latching cams. The cams were cut from 316 stainless steel to provide corrosion resistance, and engaged stainless eyebolts at either end of the float package. The cams were arranged so that extension springs would return them to an open position when the release unit was commanded to function. The cams were held in the cocked position by stainless steel cables terminating in insulated blocks which were connected by nichrome burn wires. The cams were isolated electrically from the aluminum float rack with nylon shoulder washers. The springs, cables and burn wires were adapted from our deep sea tripod release with one additional feature. A stainless steel turnbuckle was added to the restraining cable assembly to allow for tensioning of the release link after the nichrome links had been established. In previous releases, we had depended on the burn wire assembly to provide the correct tension when installed. This simple design modification allows the operator to assemble the burn link without tension on it, greatly simplifying the task, and increasing operator safety. A drawing showing the release features is presented in Figure 4.

The insulating blocks mentioned above are fabricated from fiberglass or some other suitable insulating material. The purpose of the blocks is to ensure that the nichrome burn wire links are totally isolated from any other part of the tripod. If a burn wire were to be electrically connected to some part of the tripod, the release might fail to function as the current required to dissolve the nichrome wire could be short circuited into some other metal component. 


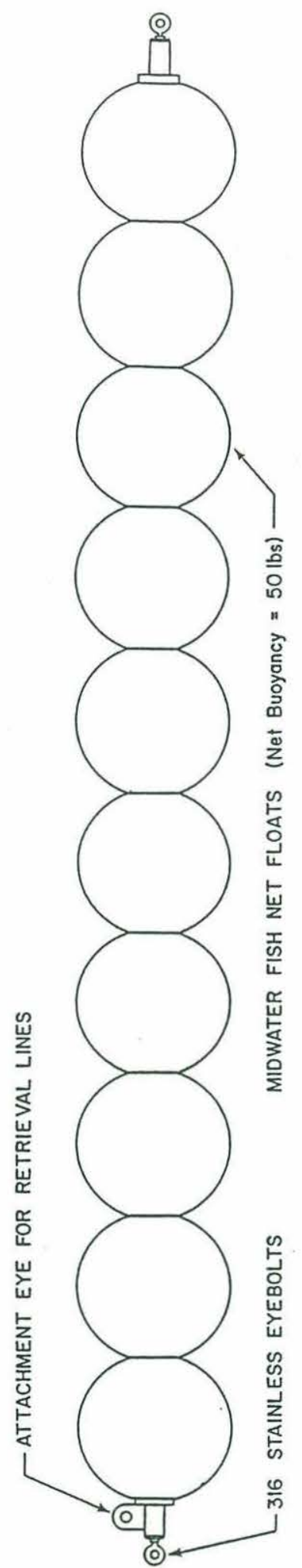

Figure 3: Completed Float Package 


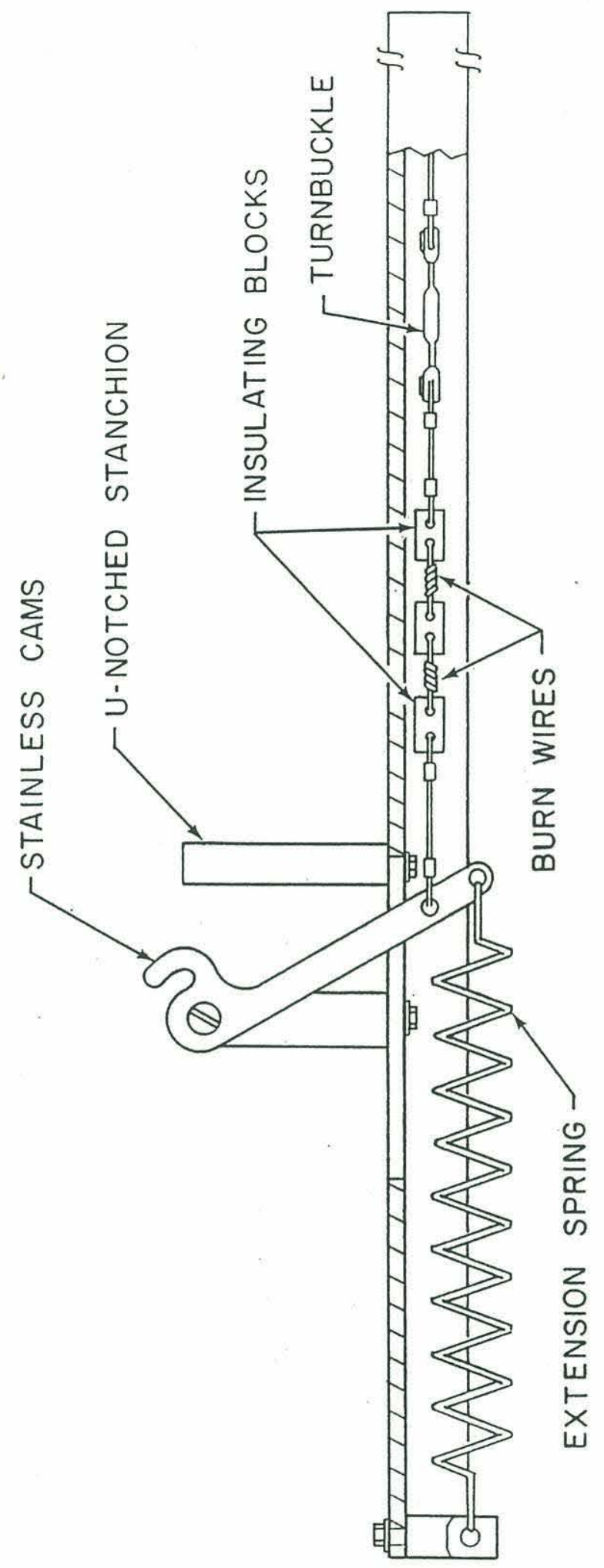

Figure 4: Drawing of Release Features 
The retrieval line, 1/2 inch diameter Samson brand 2 in 1 braid, is easy to handle on deck, strong enough to lift the tripod even with moderate damage, and has excellent resistance to abrasion because of its outer sheath. This line was selected based our previous experience in CODE, where a tripod was lost because a smaller, less abrasion resistant line was used. The line was spooled into a storage canister made from milk crates. The canister was lined with a stiff plastic mesh material to keep the line in place and to prevent a loop from spilling out of the side holes. The open construction of the milk crates was preferred to allow the canisier to flood freely during tripod deployment, preventing trapped air bubbles from displacing or moving the stored line. The line was spooled into the canister in a carefully controlled lay pattern drawn from the experience of the New England whaling fleet. Our intention was to ensure that the line could pay out freely, and yet be stored in as small a canister as possible. The canister and rope packing techniques are illustrated in Figure 5.

The BASS tripods have an instrument platform approximately 12 feet above the bottom: The line canister was mounted on this platform where it would be free from obstructions. The float rack and package were also attached to the tripod on this platform, but mounted to the side so that the float package would be free to rise without obstructions above. The line was dressed from the float to the canister along the tripod frame.

It was secured with 10 pound test monofilament line to prevent unwanted motion of the line. In addition, an exposed run of the lifting line was encased in a length of split garden hose to keep it from being pulled loose by wave action during deployment. The monofilament line was tested with a tension metering device to ensure that its strength was not significanlly greater than the listed rating. The float package had approximately 50 pounds of positive buoyancy, which was adequate to overcome the restraint offered by the 10 pound monofilament line.

\section{$5 \quad$ Field Experience}

The recovery package described here was used as the primary retrieval system during the STRESS experiment. The system was attached to a total of four tripods which were deployed for five months. During this time, each tripod was recovered twice, once for servicing at the experiment midpoint, and once for final retrieval. All of the systems fired successfully on command, releasing the float package from its restraining cradle. In all but one recovery attempt, the float pulled the recovery line to the surface allowing for a normal recovery using the ship's winch and crane. The single failure was caused by the recovery line fouling in the rope canister, preventing the float package from reaching the surface. This tripod was recovered using an ROV to attach an alternate lifting line to the tripod. This method was used because the tripod was too deep for simple diver recovery.

During the five months of deployment the system did experience some corrosion problems. In particular, the tab which connected the lifting line to the float package suffered from severe corrosion. Excessive corrosion at this point would result in the failure of the connection 


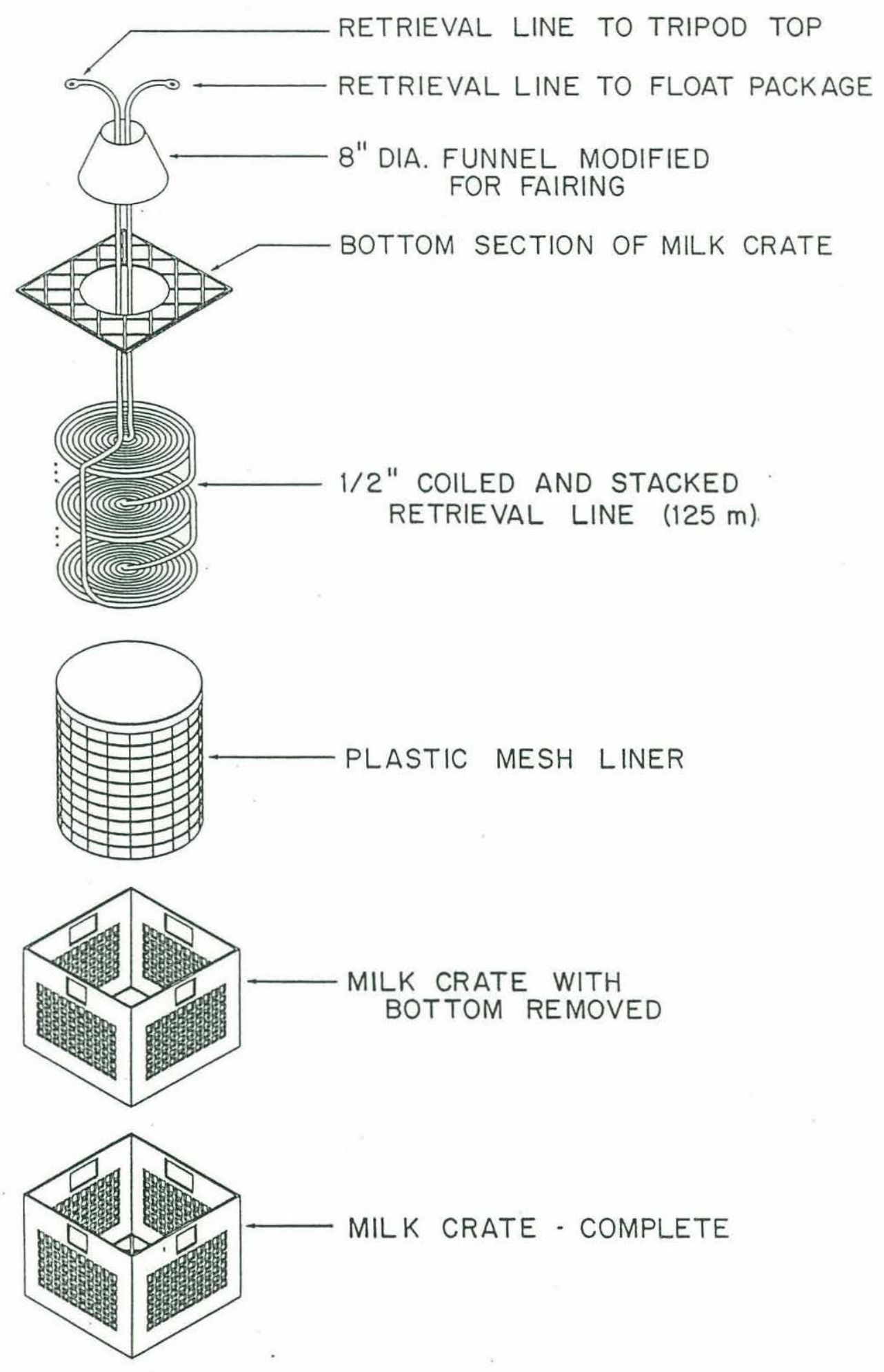

Figure 5: Illustration of Canister and Rope Packing Techniques 
between the float package and the lift line, allowing the float to surface without the recovery line. This could result in the loss of the tripod if an alternate recovery means were not available. We first discovered the problem when the tripods were recovered for servicing after two and one half months of deployment. At that time, we added a zinc anode to the float rack to slow the loss of material, and also added a safety line to the attachment so that the float would remain attached to the lifting line even if the attachment point failed completely. A more subtle failure was also possible from corrosion effects. The restraints holding the individual trawl floats to the rack assembly also suffered some corrosion damage. If these were to fail, the individual floats would be free to rise to the surface without the rack or attached lifting line when the release was fired.

The most serious problem that we encountered during the actual deployment was the failure of a single float to arrive at the surface when commanded due to line fouling. The tripod involved had pre-released early in the experiment and been redeployed. The pre-release * occurred within hours of launching the tripod and was discovered to have been caused by an error in configuring the release electronics. A backup timer circuit was inadvertently left in test mode causing the release to fire prematurely. Once the pre-release was discovered, the tripod involved was recovered, the release was rearmed, the lifting line was carefully repacked in the rope canister, and the tripod was redeployed. Study of the rope canister and its contents after the ROV recovery did not yield any clues other than the observation that the lift line had thrown a loop around the tightly coiled contents inside the canister and the float had been unable to pull this blockage through the narrow opening of the rope canister. It is possible that the problem was caused by the repacking of the rope canister, although similarly repacked equipment worked as expected. It was not possible to closely inspect the fouled equipment with the camera on the ROV during the rescue operation so no further conclusions about the cause of the single failure are possible. It is reported here, however, as a cautionary note to users of this system to point out the importance of proper assembly of the various components of this type of release system. As a further safeguard against this type of failure, it is possible that the lid of the rope canister should be fastened with monofilament line. This would allow the float package to pull the entire block of recovery line free if it tangled and possibly provide enough slack for the float to reach the surface. We have not tried this alternative and do not recommend it without engineering trials to assess problems that might be introduced by this change in configuration.

In spite of the single failure discussed above, the overall success of the system was extremely good. A prototype unit was assembled and tested in Woods Hole before committing to a final design. The experience in the test showed that the conceptual design was satisfactory, and some minor modifications in materials and assembly techniques were incorporated in the units constructed 'for field use. In total, eight deployment recovery cycles were performed including the dock test in Woods Hole. Of these eight cycles, only a single failure was noted, and that was of the recovery line payout, not the latch portion of the mechanism. Extra care should be taken in packing the rope canister because it is the only component of the system which has demonstrated a failure mode. The use of zinc anodes to protect the alloy portions of the float rack is also recommended, along with the use of a corrosion resistant alloy. Some of the prototype components were fabricated with alloy of unknown composition. 
The parts which were known to be 6061 alloy exhibited excellent corrosion resistance during the extended deployments.

\section{Conclusions}

The recovery system described in this report is an appropriate tool to use in oceanographic studies where the recovery of the entire instrument package including the anchor weight is desired. The pop up float can be used to pull a strong recovery line to the surface so that the entire sub-surface assembly can be retrieved. The float package has a buoyancy of 50 pounds as described here but could be enlarged to allow for additional lift if desired. The lift line described here is a one half inch diameter Dacron line with a safe lifting capacity of about five thousand pounds. This was well in excess of our need to recover approximately 1000 " pounds, but provided an excellent safety margin for our operations. In addition, the half inch sheathed line has proven to be a very comfortable line to work with in the field.

The system described here will not be appropriate for all situations. In particular, deployments in areas with high currents or greater depth may require additional buoyancy for successful operation due to current drag and dead weight loading on the lift line. These effects should be investigated before selecting this system for a specific application. The float rack we deployed had no lighting on it which would have made night recovery operations difficult. For recovery at night some type of lighting and/or reflective tape is recommended.

We did find that the system described here performed well under the conditions we experienced. The water depth was approximately 90 meters, and the currents in the area were one knot or less. The float could pull the half inch lift line to the surface in about ten to fifteen minutes, and then keep the line on the surface until recovered by the ship. We did limit the length of the line, working with a scope of approximately 1.25 to 1 , requiring the ship to position itself immediately above the underwater package being recovered. This was done to prevent dragging during the recovery phase of the operation. For packages less sensitive to dragging damage, a longer scope would be recommended to allow for easier handling of the lift line once aboard the recovery ship. 


\section{Appendix A}

\section{Engineering Drawings}

This appendix contains a set of twelve drawings which show the components required to build the release and float system described in this report. The drawings presented here are numbered in accordance with the drawing library maintained by Dr. Albert J. Williams 3rd, for whom this work was performed.

Drawing Number

Description

AJW-M-0020C

Main Support Channel

AJW-M-0021C

AJW-M-0318B

Float Support Pipe Assembly

AJW-M-0319B

Latch, Stainless Steel

AJW-M-0320B

Latch Pedestal

AJW-M-0321B

Spring Holder

AJW-M-0322B

AJW-M-0323B

AJW-M-0324B

AJW-M-0325B

AJW-M-0326B

AJW-M-0018D

Float Support Block

Lift Line Tab

Float Retainer Ring I

Float Retainer Ring II

Float Rack End Plug

Alignment Block

Assembly Drawing 


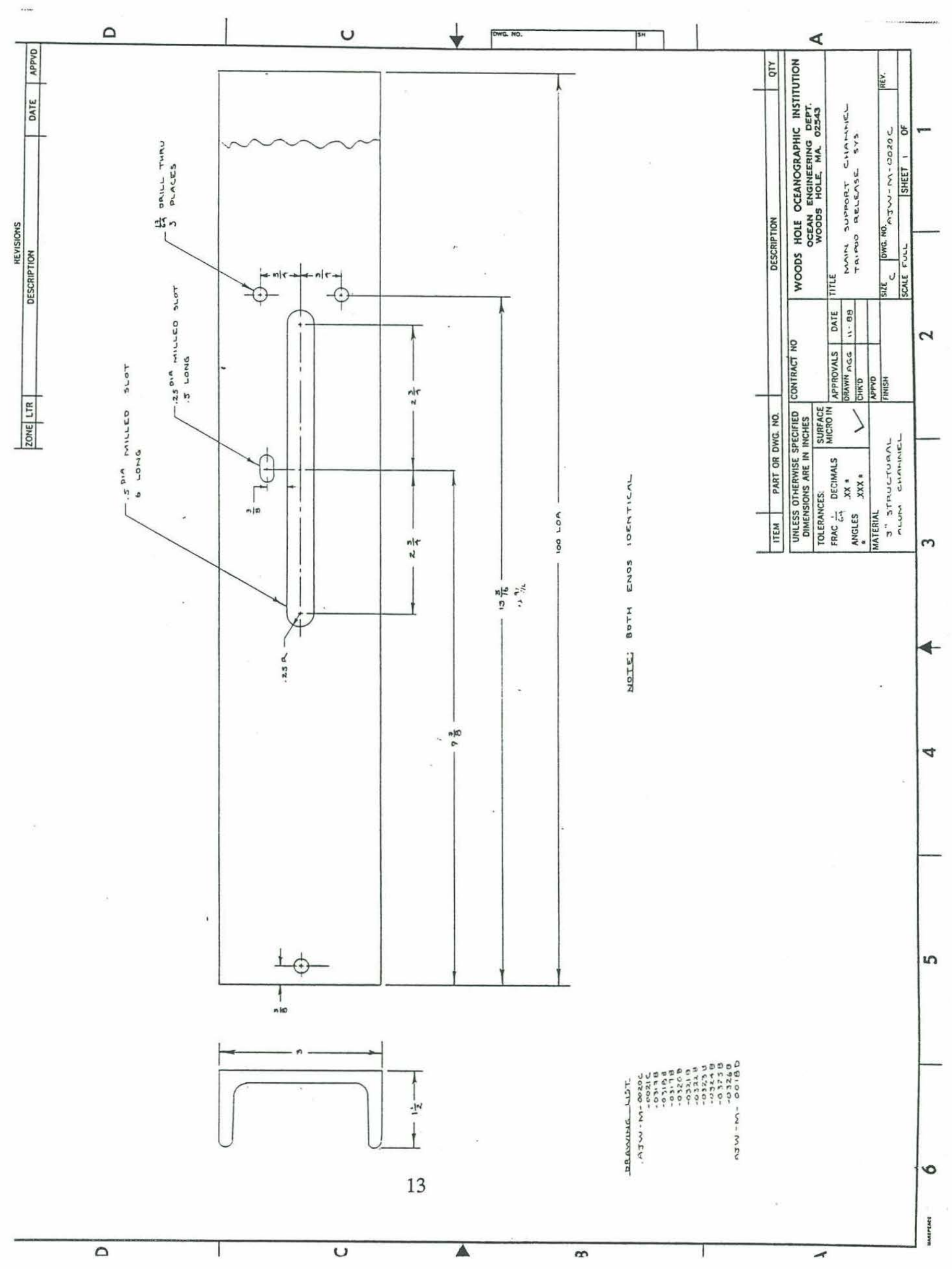




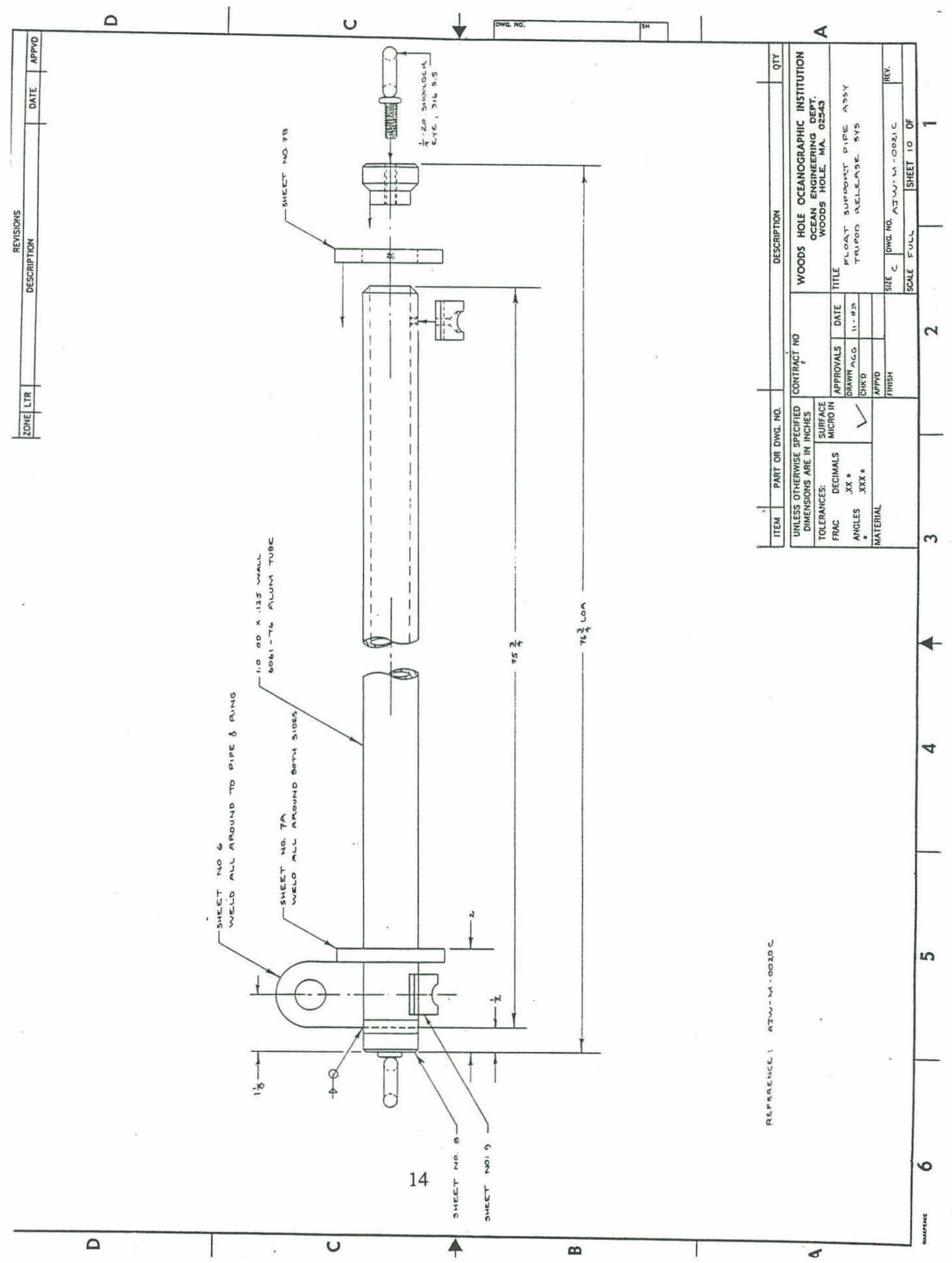




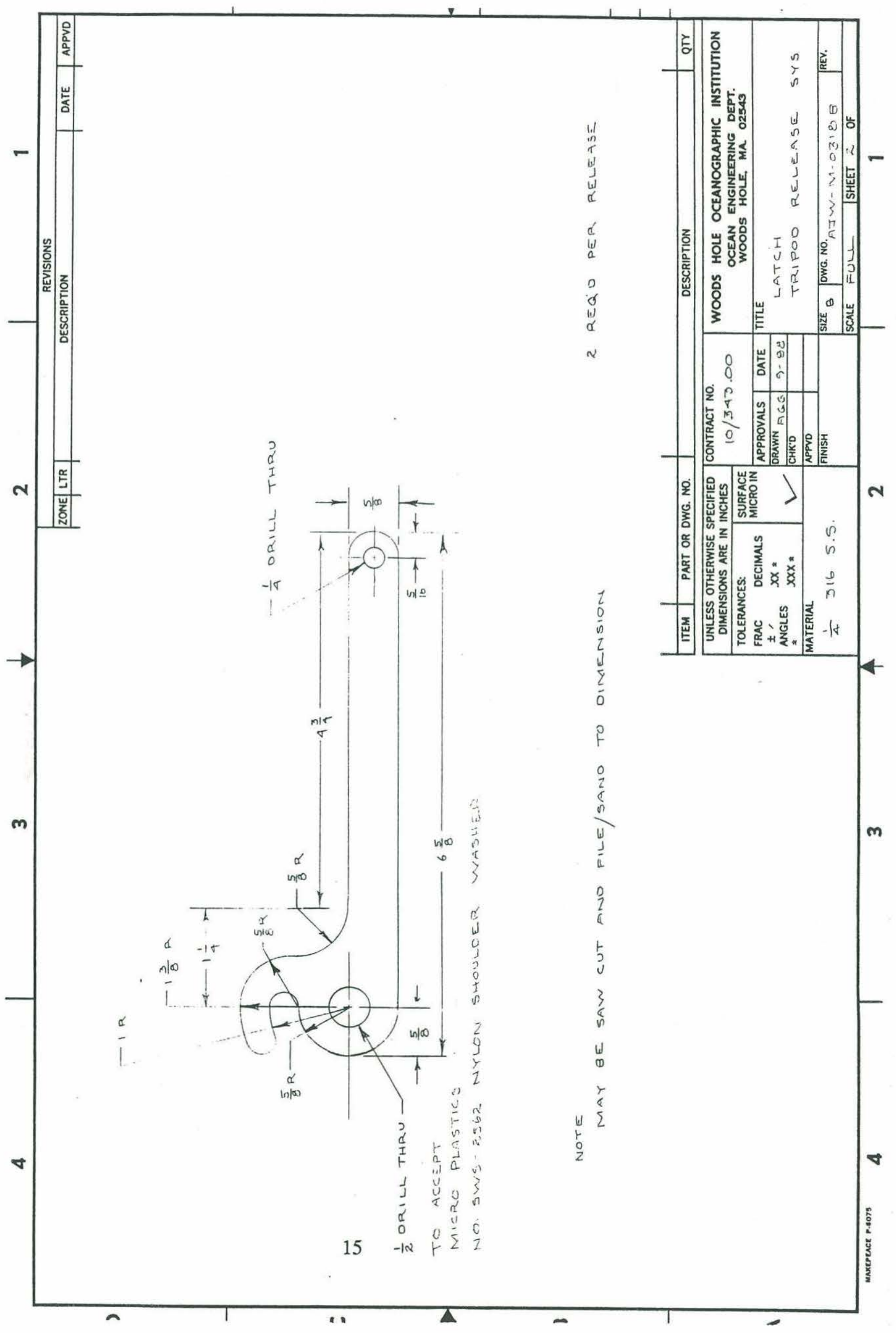




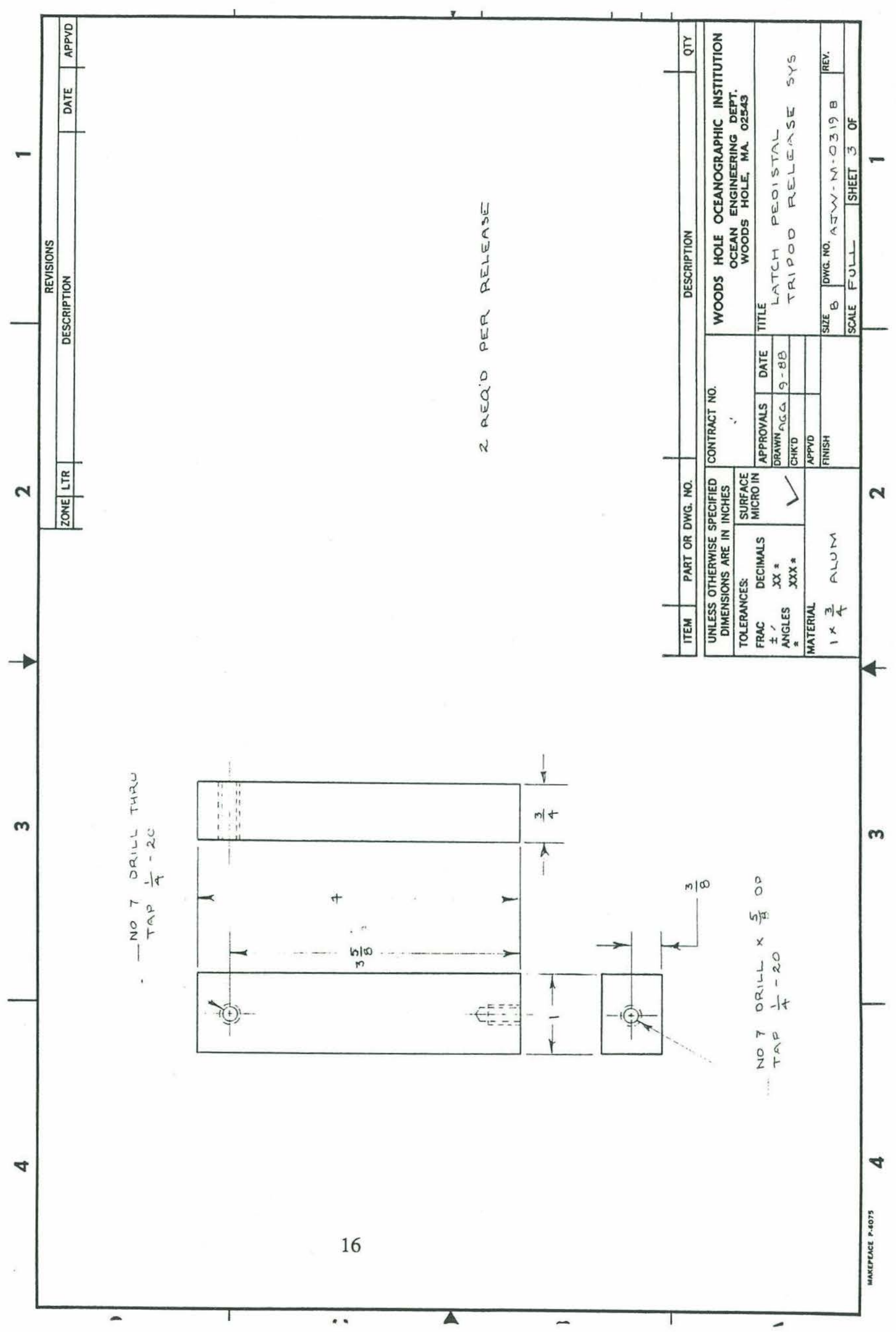




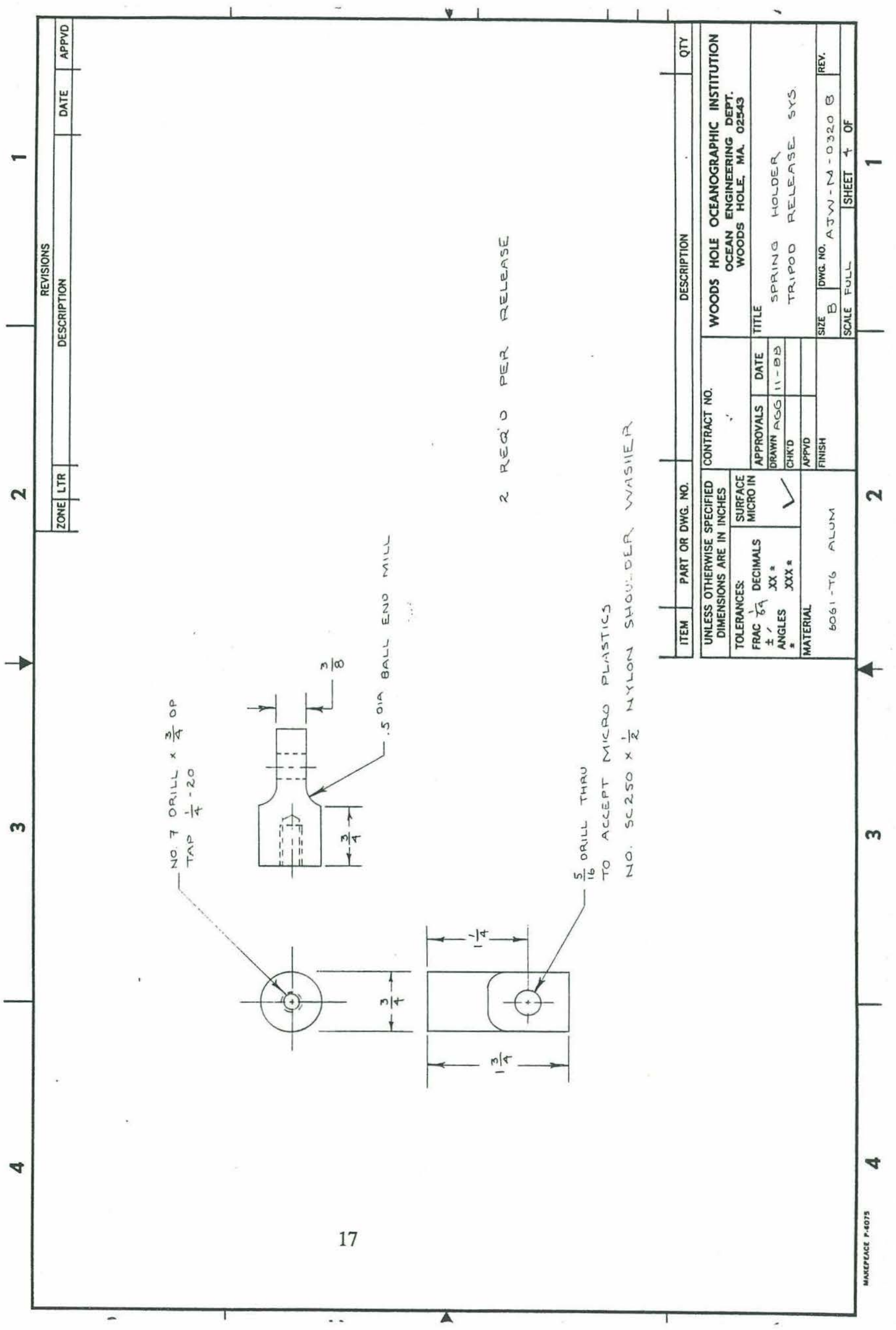




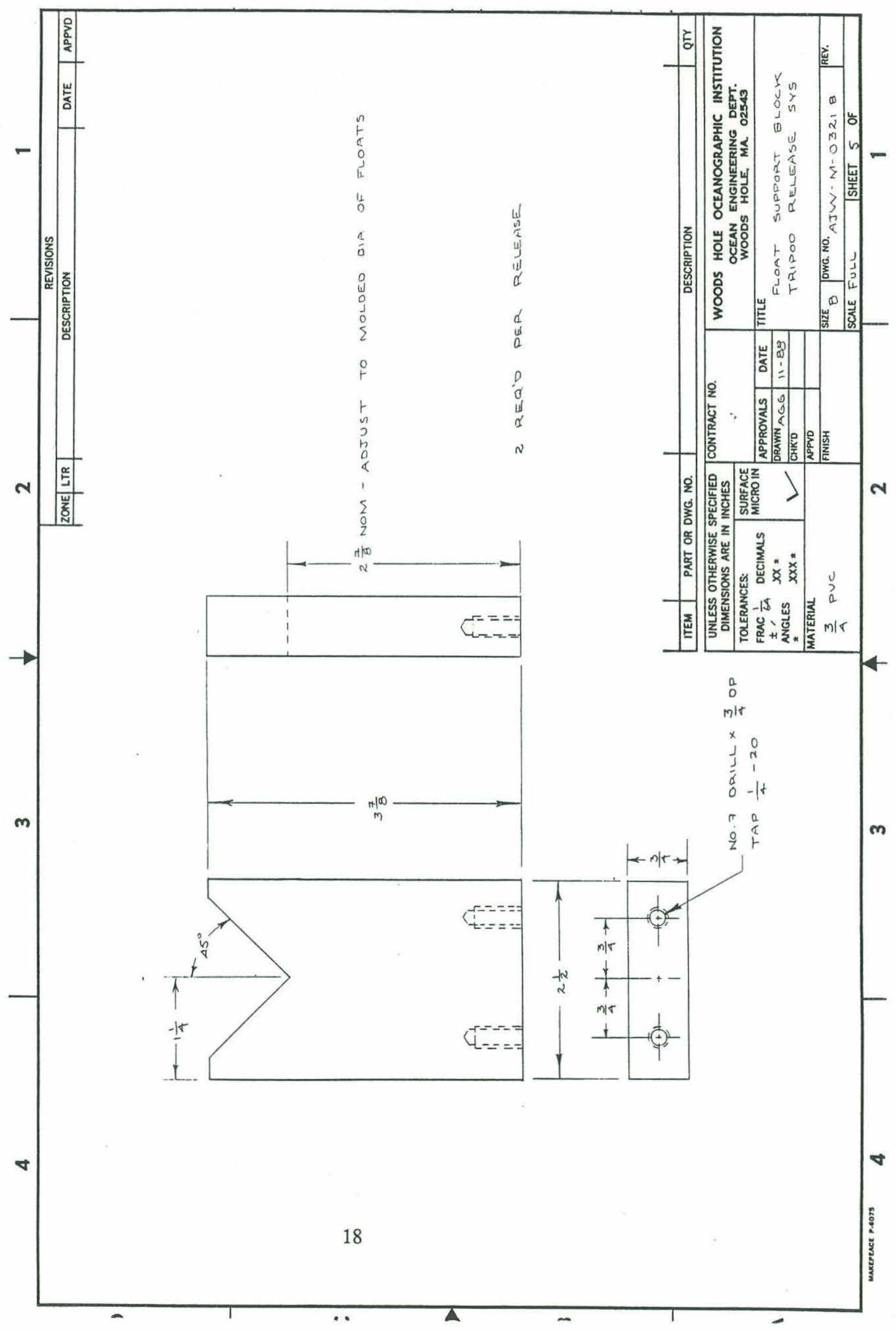




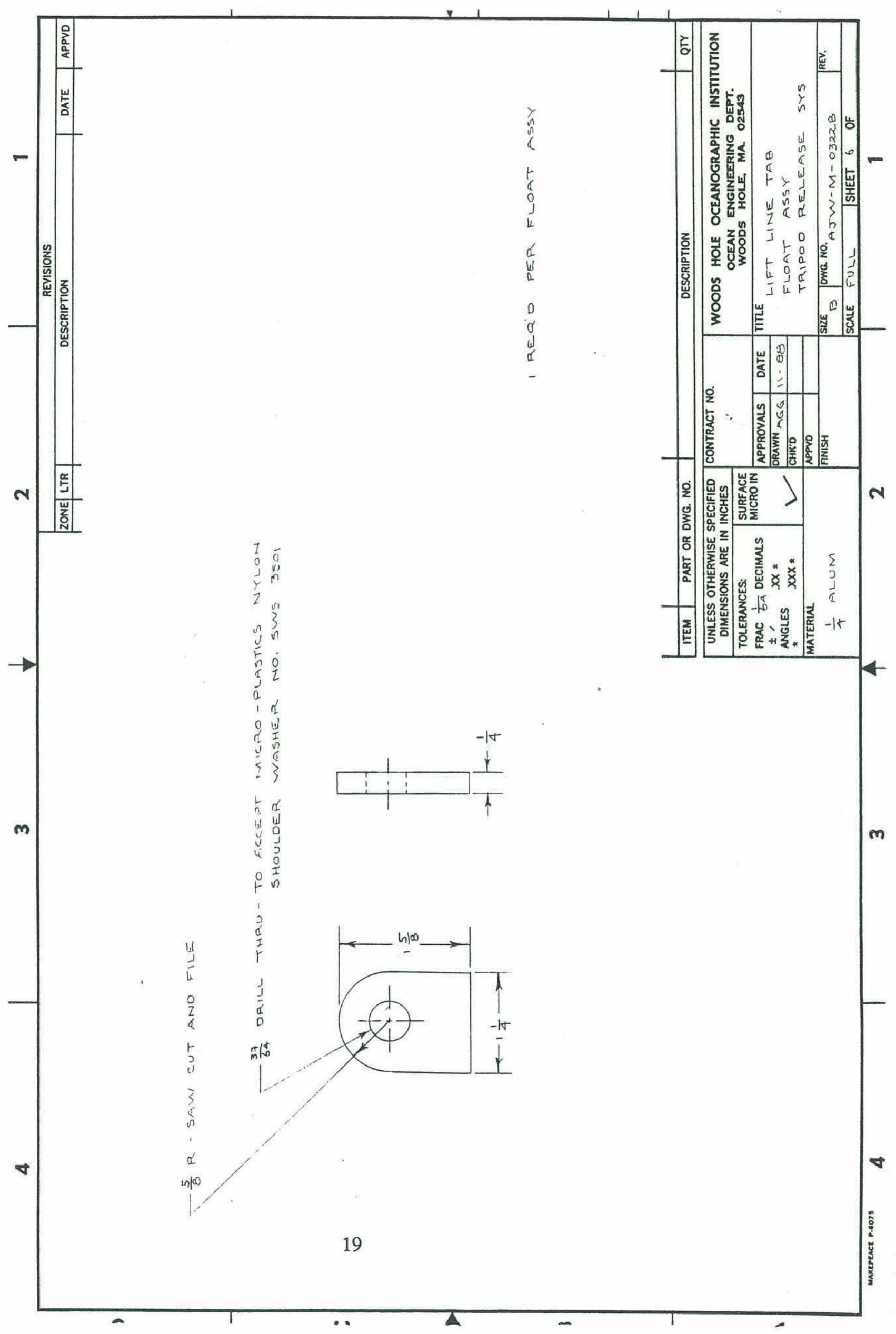




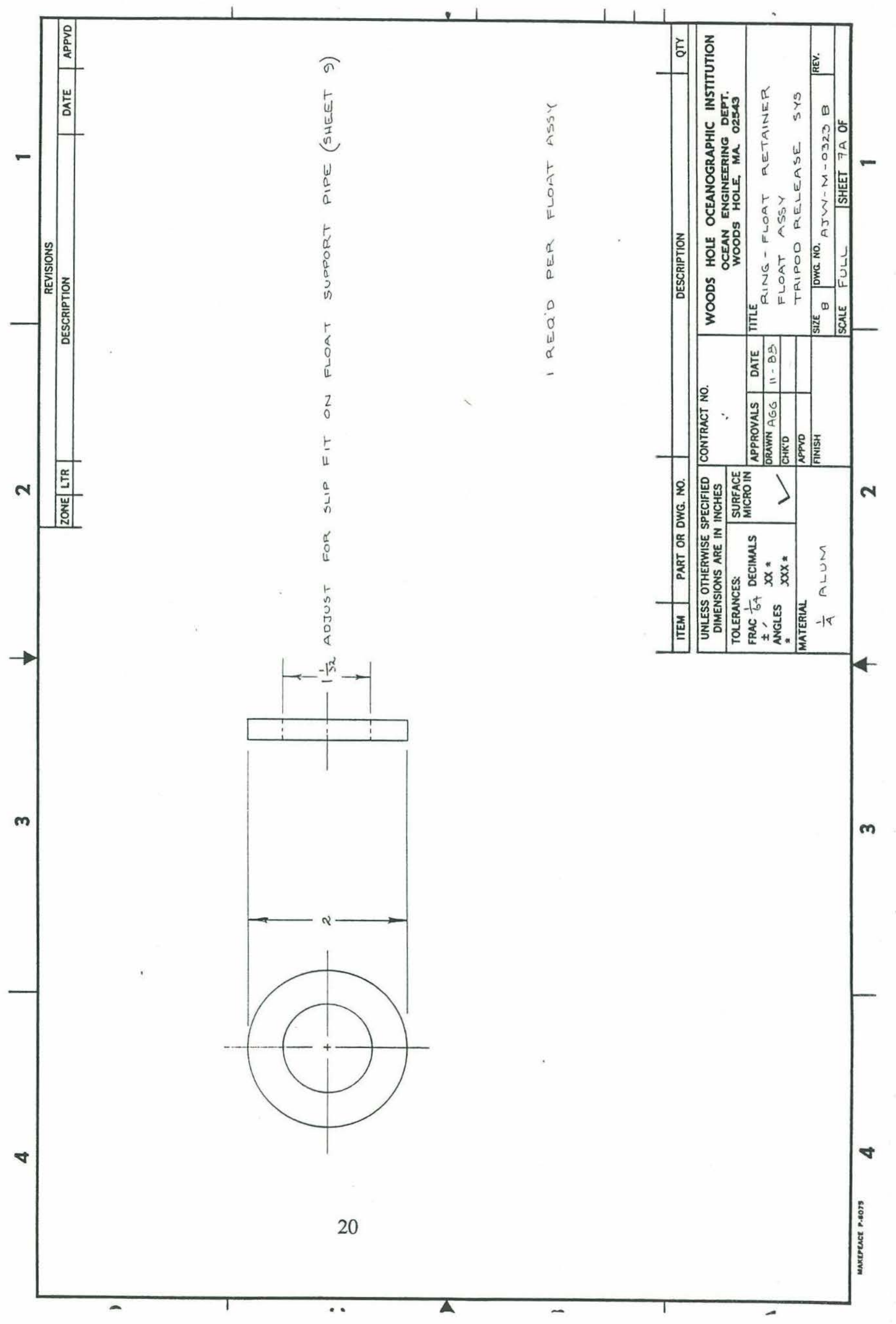




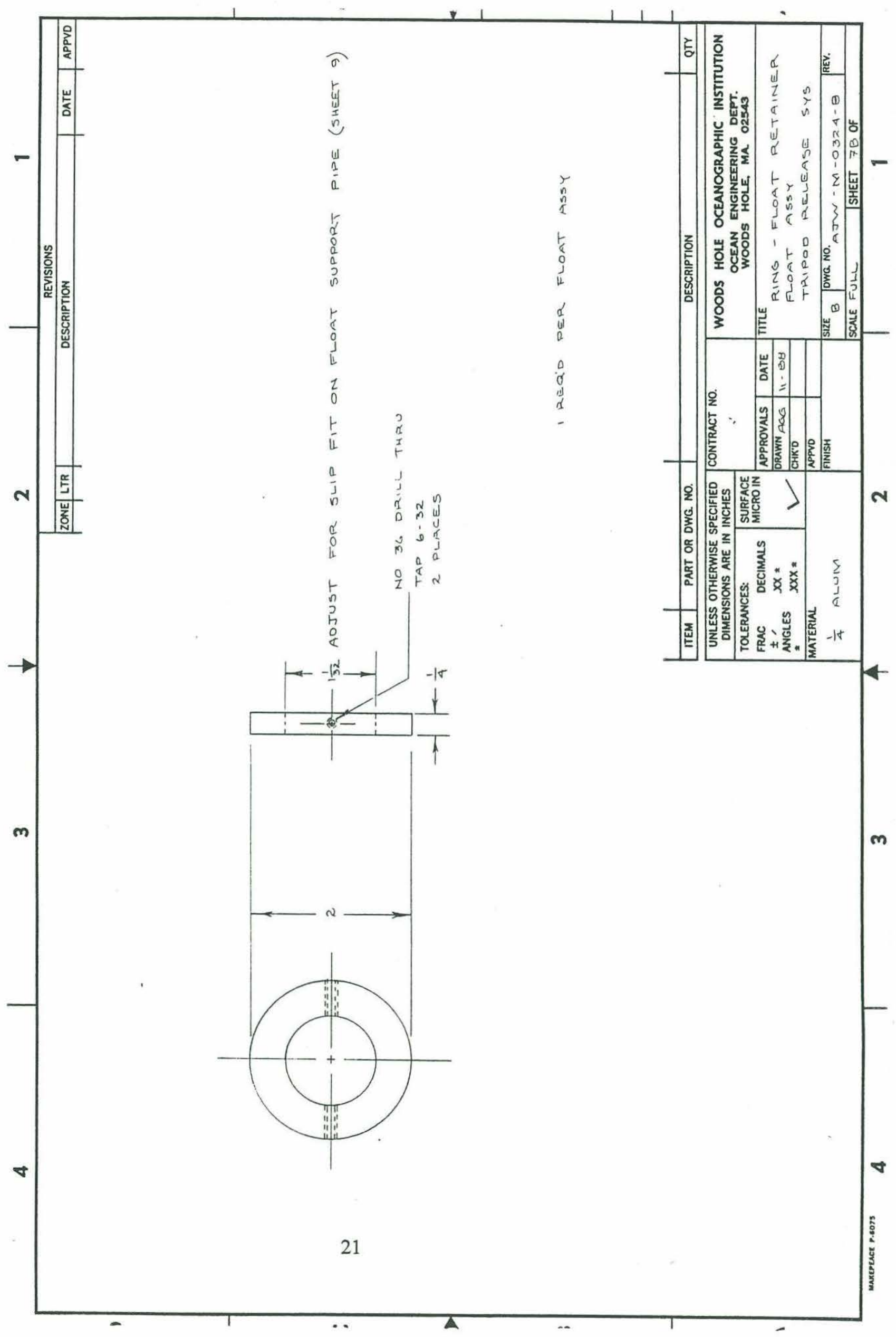




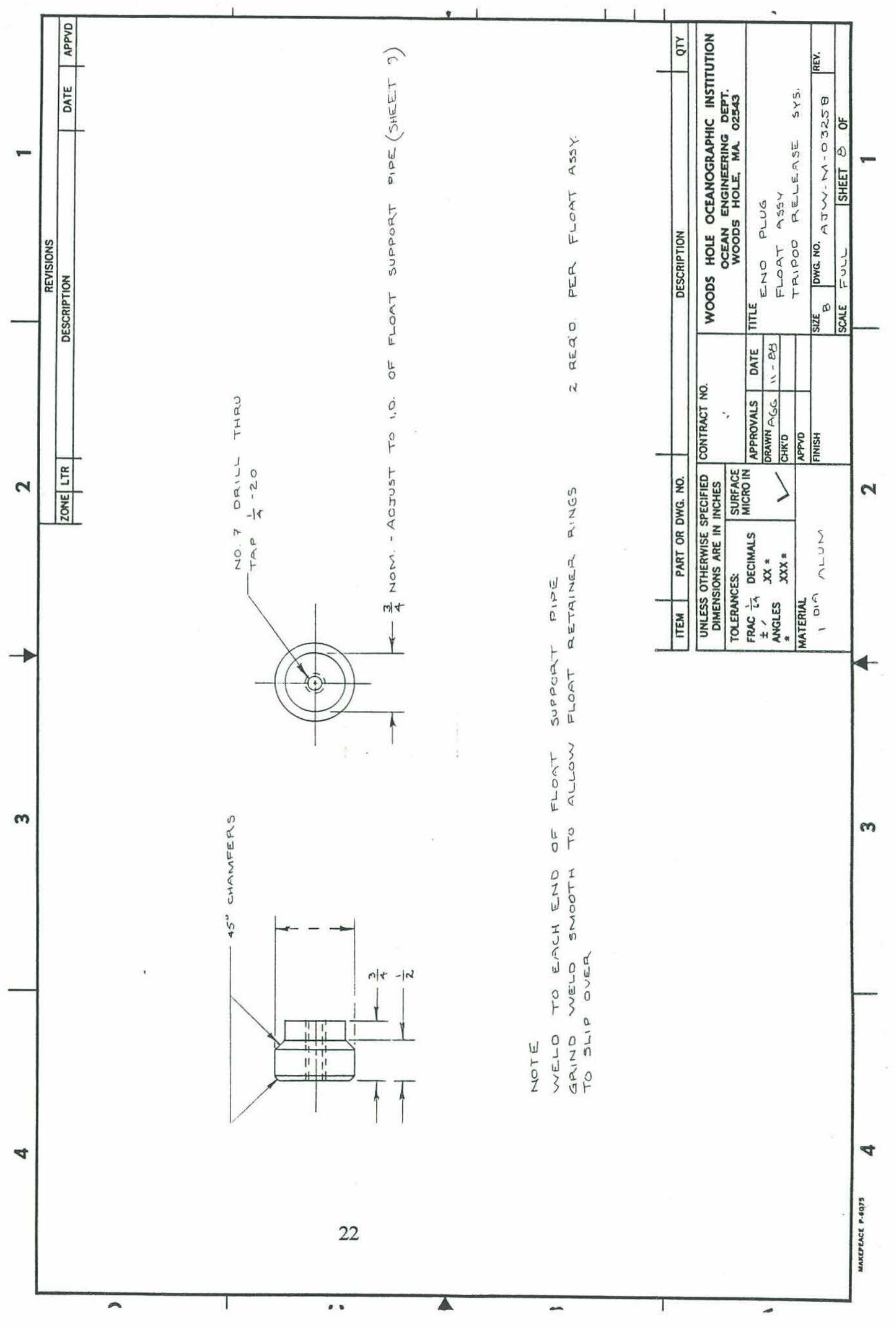




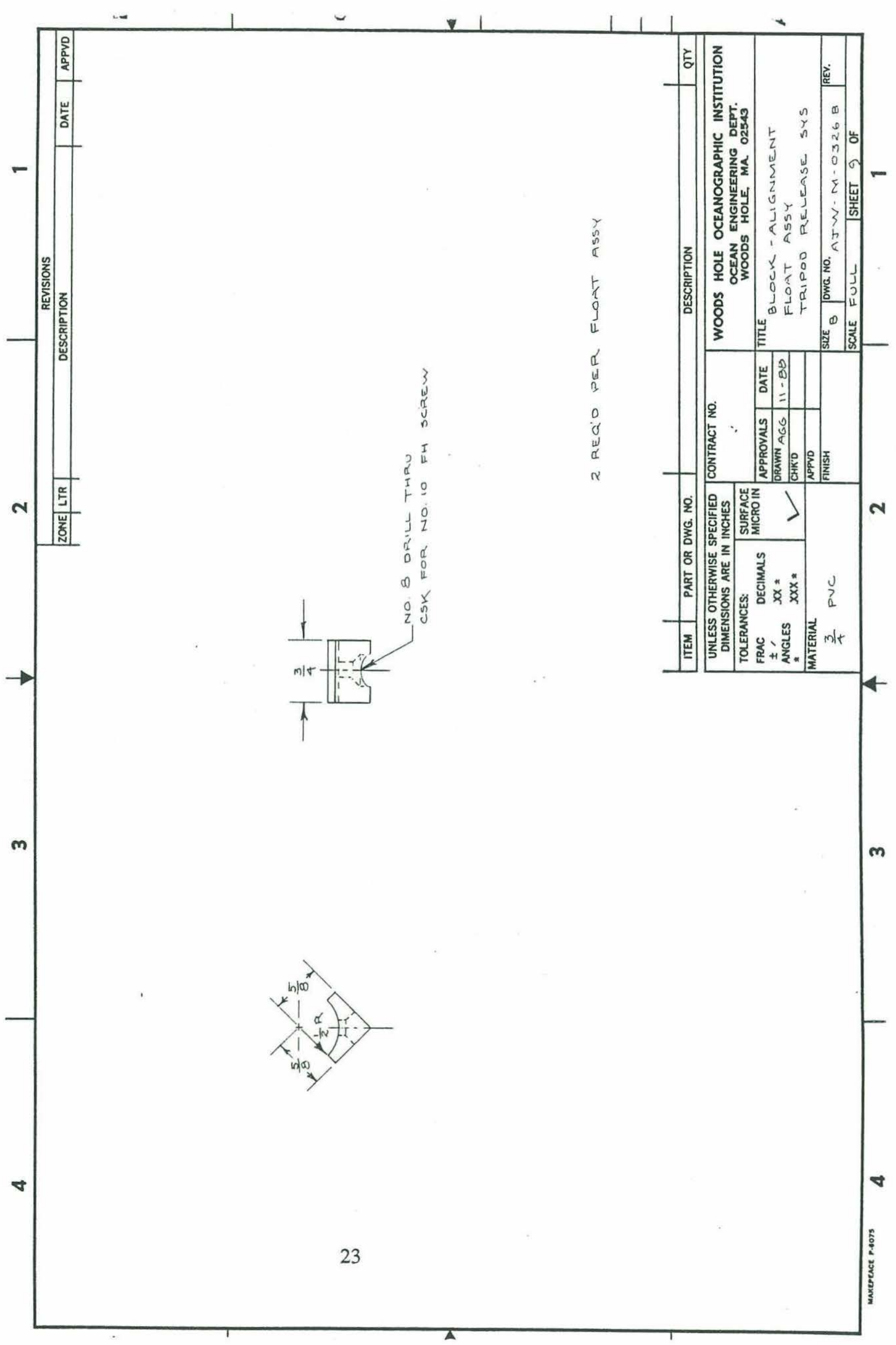




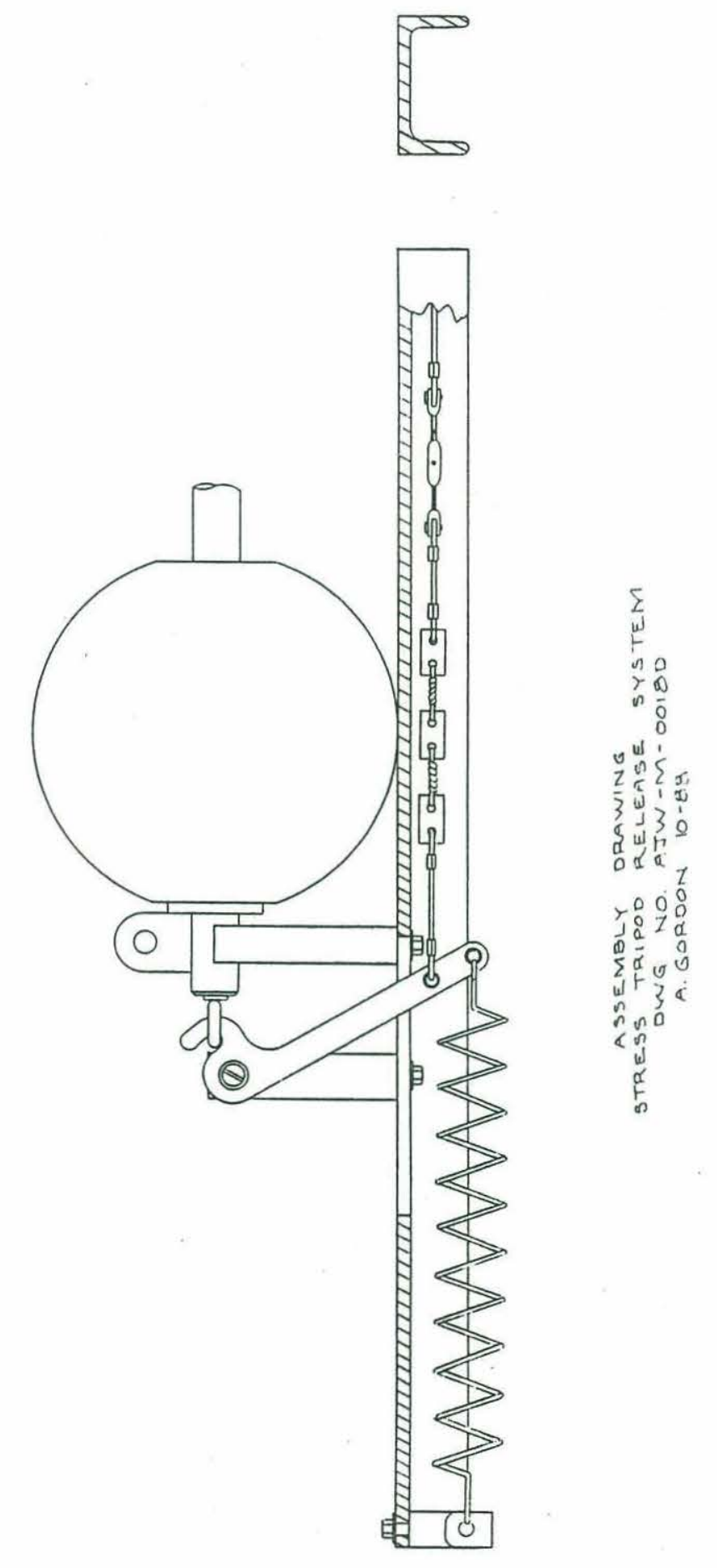




\section{Appendix B}

\section{List of Vendors}

This appendix lists components supplied by commercial vendors. Enough information is provided to duplicate the components through either the same vendor or an alternate source.

IMP Fishing Gear Ltd. 44 South Street

New Bedford, MA 02740

Internet, Inc.

2730 Nevada Avenue North

Minneapolis, Minnesota 55427

Samson Rope

99 High Street

Boston, MA 02110
"Iceplast" \#1085 Trawl Float (made in Iceland)

$\frac{1}{2}^{\prime \prime} \mathrm{x} \frac{1}{2}^{\prime \prime}$ polystyrene mesh

Samson "2 in 1 " double braid rope

$\frac{1}{2}$ " diameter

average breaking strength: 8,500 lbs. 


\section{DOCUMENT LIBRARY}

July 5, 1989

Distribution List for Technical Report Exchange

Attn: Stella Sanchez-Wade

Documents Section

Scripps Institution of Oceanography

Library, Mail Code C-075C

La Jolla, CA 92093

Hancock Library of Biology \& Oceanography

Alan Hancock Laboratory

University of Southern California

University Park

Los Angeles, CA 90089-0371

Gifts \& Exchanges

Library

Bedford Institute of Oceanography

P.O. Box 1006

Dartmouth, NS, B2Y 4A2, CANADA

Office of the International

Ice Patrol

c/o Coast Guard R \& D Center

Avery Point

Groton, CT 06340

Library

Physical Oceanographic Laboratory

Nova University

8000 N. Ocean Drive

Dania, FL 33304

NOAA/EDIS Miami Library Center

4301 Rickenbacker Causeway

Miami, FL 33149

Library

Skidaway Institute of Oceanography

P.O. Box 13687

Savannah, GA 31416

Institute of Geophysics

University of Hawaii

Library Room 252

2525 Correa Road

Honolulu, HI 96822

Library

Chesapeake Bay Institute

4800 Atwell Road

Shady Side, MD 20876

MIT Libraries

Serial Journal Room 14E-210

Cambridge, MA 02139
Director, Ralph M. Parsons Laboratory Room 48-311

MIT

Cambridge, MA 02139

Marine Resources Information Center

Building E38-320

MIT

Cambridge, MA 02139

Library

Lamont-Doherty Geological Observatory

Colombia University

Palisades, NY 10964

Library

Serials Department

Oregon State University

Corvallis, OR 97331

Pell Marine Science Library

University of Rhode Island

Narragansett Bay Campus

Narragansett, RI 02882

Working Collection

Texas A\&M University

Dept. of Oceanography

College Station, TX 77843

Library

Virginia Institute of Marine Science

Gloucester Point, VA 23062

Fisheries-Oceanography Library

151 Oceanography Teaching Bldg.

University of Washington

Seattle, WA 98195

Library

R.S.M.A.S.

University of Miami

4600 Rickenbacker Causeway

Miami, FL 33149

Maury Oceanographic Library

Naval Oceanographic Office

Bay St. Louis

NSTL, MS 39522-5001

Marine Sciences Collection

Mayaguez Campus Library

University of Puerto Rico

Mayagues, Puerto Rico 00708 


\begin{tabular}{|c|c|c|c|}
\hline $\begin{array}{l}\text { REPORT DOCUMENTATION } \\
\text { PAGE }\end{array}$ & $\begin{array}{l}\text { 1. REPORT NO. } \\
\text { WHOI-89-52 }\end{array}$ & 2. & 3. Recipient's Accession No. \\
\hline \multirow{2}{*}{\multicolumn{3}{|c|}{$\begin{array}{l}\text { 4. Title and Subtitle } \\
\text { A Pop-up Float Recovery System For Coastal Oceanographic Tripods }\end{array}$}} & $\begin{array}{l}\text { 5. Report Date } \\
\text { November, } 1989\end{array}$ \\
\hline & & & 6. \\
\hline \multicolumn{3}{|c|}{$\begin{array}{l}\text { 7. Author(s) } \\
\text { Christopher V.R. Dunn and Allan G. Gordon }\end{array}$} & $\begin{array}{l}\text { 8. Performing Organization Rept. No. } \\
\text { WHOI-89-52 }\end{array}$ \\
\hline \multirow{2}{*}{\multicolumn{2}{|c|}{$\begin{array}{l}\text { 9. Performing Organization Name and Address } \\
\text { The Woods Hole Oceanographic Institution } \\
\text { Woods Hole, Massachusetts } 02543\end{array}$}} & & 10. Project/Task/Work Unit No. \\
\hline & & & $\begin{array}{l}\text { 11. Contract(C) or Grant(G) No. } \\
\text { (C) } \\
\text { (G) ONR N00014-89-J-1058 }\end{array}$ \\
\hline \multirow{2}{*}{\multicolumn{2}{|c|}{$\begin{array}{l}\text { 12. Sponsoring Organization Name and Address } \\
\text { Funding was provided by the Office of Naval Research }\end{array}$}} & & $\begin{array}{l}\text { 13. Type of Report \& Period Covered } \\
\text { Technical Report }\end{array}$ \\
\hline & & & 14. \\
\hline
\end{tabular}

15. Supplementary Notes

This report should be cited as: Woods Hole Oceanog. Inst. Tech. Rept., WHOI-89-52

16. Abstract (Limit: 200 words)

The recovery package described here was used as the primary retrieval system to recover tripod instrument platforms from a depth of 90 meters. The device uses dual in-line burn wires, one of which is acoustically commanded from the surface ship. The other is set to release by back-up timer, ensuring recovery in the event of a poor acoustic command channel. The burn wire activates spring loaded cam latches which release the float package and pull a $1 / 2$ inch Dacron line to the surface. The float package is recovered and the line is used to winch the tripod to the surface for recovery by the ship's crane. Major benefits of the system are reliability, low cost, light weight, and use of many off-the-shelf components. The float package provides 50 pounds of buoyancy and is fabricated using commercial fish trawl net floats. The retrieval line container is separate from the float assembly, and is fabricated from plastic storage containers. The line is coiled and restricted to prevent unpackaging due to waves or current action. The system described here is not appropriate in areas of high current or great depth due to drag and dead weight of the lift line.

\section{Document Analysis a. Descriptors}

1. tripod float release

2. release for tripod float

3. pop-up float release

b. Identifiers/Open-Ended Terms

c. COSATI Field/Group

18. Availability Statement

Approved for publication; distribution unlimited.

\begin{tabular}{|l|l|}
\hline $\begin{array}{c}\text { 19. Security Class (This Report) } \\
\text { UNCLASSIFIED }\end{array}$ & $\begin{array}{c}\text { 21. No. of Pages } \\
25\end{array}$ \\
\hline 20. Security Class (This Page) & 22. Price \\
\hline
\end{tabular}

OPTIONAL FORM 272 (4-77) 